УДК 33

DOI $10.21661 / \mathrm{r}-117054$

\title{
Е.П. Солодова
}

\section{МЕТОДОЛОГИЧЕСКИЕ ОСНОВЫ УПРАВЛЕНИЯ РАЗВИТИЕМ МАЛЫХ ПРЕДПРИНИМАТЕЛЬСКИХ СТРУКТУР В ЖИЛИЩНО-КОММУНАЛЬНОМ ХОЗЯЙСТВЕ}

Аннотация: в статье актуализируется необходимость четкого разграничения дефиниций «рост» и «развитие» применительно к процессу управления развитием малых предпринимательских структур. Дано авторское толкование понятия «малая предпринимательская структура в ЖКХ». Разработана модель управления развитием мальх предпринимательских структур в ЖКХ.

Ключевые слова: малье предпринимательские структуры, жилищно-коммунальное хозяйство, управление развитием, малье предприятия.

\section{E.P. Solodova}

\section{METHODOLOGICAL BASIS OF THE DEVELOPMENT MANAGEMENT OF SMALL BUSINESSES IN HOUSING AND UTILITIES INFRASTRUCTURE}

Abstract: the article analyzes the mainstreaming of necessary distinction between «growth» and «development» definitions, applied to the process of development man-

agement of small enterprises. There is the author's interpretation of the concept of «small businesses in housing and utilities infrastructure». The management model was designed for the development management of small businesses in housing and utilities infrastructure.

Keywords: small businesses, housing and utilities infrastructure, development management, small enterprises. 
В условиях современной экономики развитие малых предпринимательских структур в жилищно-коммунальном хозяйстве (далее ЖКХ) не может быть результативным, если не будет сформирован эффективный механизм управления и не будет решен ряд проблем методологического характера.

Так исследователи очень часто отождествляют понятия «малое предпринимательство» и «малая предпринимательская структура», что ведет к искажению экономической сущности данных понятий.

К предпринимательству в сфере ЖКХ следует относить деятельность, направленную на производство, оказание жилищно-коммунальных услуг с последующей их реализацией потребителям, и, следовательно, под предпринимательской структурой в ЖКХ подразумеваются определенные предприятия, участвующие в данном процессе.

Под малой предпринимательской структурой (далее - МПС) в жилищнокоммунальном хозяйстве нами понимается субъект экономических отношений, основной целью которого является получение прибыли за счет оказания жилищно-коммунальных услуг, масштаб и организационно-правовая форма которого ограничены действующим законодательством (численность сотрудников, объем выручки, доля государственного участия), а именно 209-Ф3 «О развитии малого и среднего предпринимательства в РФ» (далее 209-Ф3).

Анализ практики функционирования субъектов малого предпринимательства, позволяет говорить о неоднозначности трактовки дефиниций «рост» и «развитие», поэтому теоретическое обоснование категории «управление развитием малых предпринимательских структур» в жилищно-коммунальном хозяйстве осуществим через призму связанных с ними понятий «управление» и «развитие». Кроме того, дифференциация регионов РФ по уровню социально-экономического развития, ресурсному обеспечению роста, также требует уточнения существующих подходов к развитию малого предпринимательства, в том числе в ЖКX.

Федеральный закон от 06.10.2003 №131-Ф3 «Об общих принципах организации местного самоуправления в Российской Федерации» к вопросам местного 
значения относит создание условий для развития малого и среднего предпринимательства.

В паспорте подпрограммы «Развитие малого и среднего предпринимательства» государственной программы РФ «Экономическое развитие и инновационная экономика» обозначена цель подпрограммы как «увеличение доли субъектов малого и среднего предпринимательства в экономике РФ к 2020 году до 44,5 единиц на 1 тыс. человек РФ» [3].

Таким образом, исходя из вышесказанного, в данной государственной программе, под развитием малого предпринимательства подразумевается соответствие планового показателя фактическому, при этом в качестве целевого индикатора также определён критерий количества созданных рабочих мест. Фактически под «развитием малого предпринимательства» в этом случае понимается «рост» количественных показателей, который следует расценивать как один из параметров развития малого предпринимательства как системы. С одной стороны, рост количественных показателей деятельности субъектов малого предпринимательства может привести к скачку в развитии предпринимательских структур, а с другой стороны, такой рост не может обеспечить решения множества проблем в предпринимательских структурах и его не стоит считать устойчивым. А само по себе развитие предпринимательских структур предполагает качественное изменение системы малого предпринимательства.

Такое искажений дефиниций «рост» и «развитие» в программах государственной поддержки субъектов малого предпринимательства встречается довольно часто, к сожалению, «ответственные исполнители государственных программ часто не воспринимают их как инструмент управления отраслью, а только как средство дополнительного финансирования [5].

В качестве инструмента поддержки субъектов малого и среднего предпринимательства также разработаны и реализуются региональные государственные программы, например, государственная программа Самарской области «Развиmие предпринимательства, торговли и туризма в Самарской области» на 2014- 
2019 годы. В качестве ожидаемых результатов реализации программы установлено «увеличение розничного товарооборота и повышение качества реализуемой продукции и предоставляемых услуг населению, увеличению внутреннего и въездного туристического потока». К положительным моментам вышеприведенной государственной программы относится появление качественных показателей достижения целей реализации программы, к которым следует отнести уровень налоговых поступлений в бюджетную систему. С нашей точки зрения, такие индикаторы как «количество проведенных выставок, мероприятий, направленных на создание положительного имиджа малого предпринимательства и пр.», «оправдывают» объемы бюджетного финансирования, но на процесс развития малого предпринимательства оказывают косвенное воздействие.

Считаем также обоснованным замечание Ананьева А.А., который отмечает необходимость включения показателей производительности труда и рентабельности при оценке уровня развития малых и средних предпринимательских структyp [1].

В настоящее время основная доля субъектов малого предпринимательства как в России, так и в Самарской области (38,5\% в 2015 году от общего количества зарегистрированных предприятий) осуществляют свою деятельность в торговле, на втором месте сфера услуг - 22,9\% [4]. Представляется необходимым разработка программ поддержки малых предпринимательских структур, занятых в производстве и оказывающих социально-значимые услуги, в том числе в жилищно-коммунальной сфере.

Отдельной программы, направленной на развитие малых предпринимательских структур в ЖКХ в Самарской области, в настоящее время не разработано.

Естественно, что процесс управления развитием предпринимательских структур в ЖКХ, требует координирующего и целенаправленного воздействия. Под управлением развитием малых предпринимательских структур в ЖКХ нами понимается целенаправленное воздействие управляющего субъекта на управляемый объект с целью изменения качественных и количественных показателей в системе малого предпринимательства в данной сфере. 
В условиях нестабильной экономики все большие требования предъявляются к управлению развитием малого предпринимательства как к системе, включающей в себя цели, функции и процесс управления (рисунок 1).

Принятие управленческих решений должно базироваться на все более полном и последовательном применении системного подхода. Это выражается в рассмотрении отдельных хозяйственных объектов любого уровня управления как особых систем, органически связанных и активно взаимодействующих с другими системами в рамках народно-хозяйственного комплекса, в выявлении роли каждой из них в общем процессе функционирования экономики. Т.е. для оценки эффективности управленческого решения необходимо определить все существенные взаимосвязи и установить его влияние с учетом этих взаимосвязей на поведение всей системы, а не только ее части [2].

Система управления развитием малого предпринимательства должна отражать своевременность, эффективность и организованность, протекающих в ней процессов. 


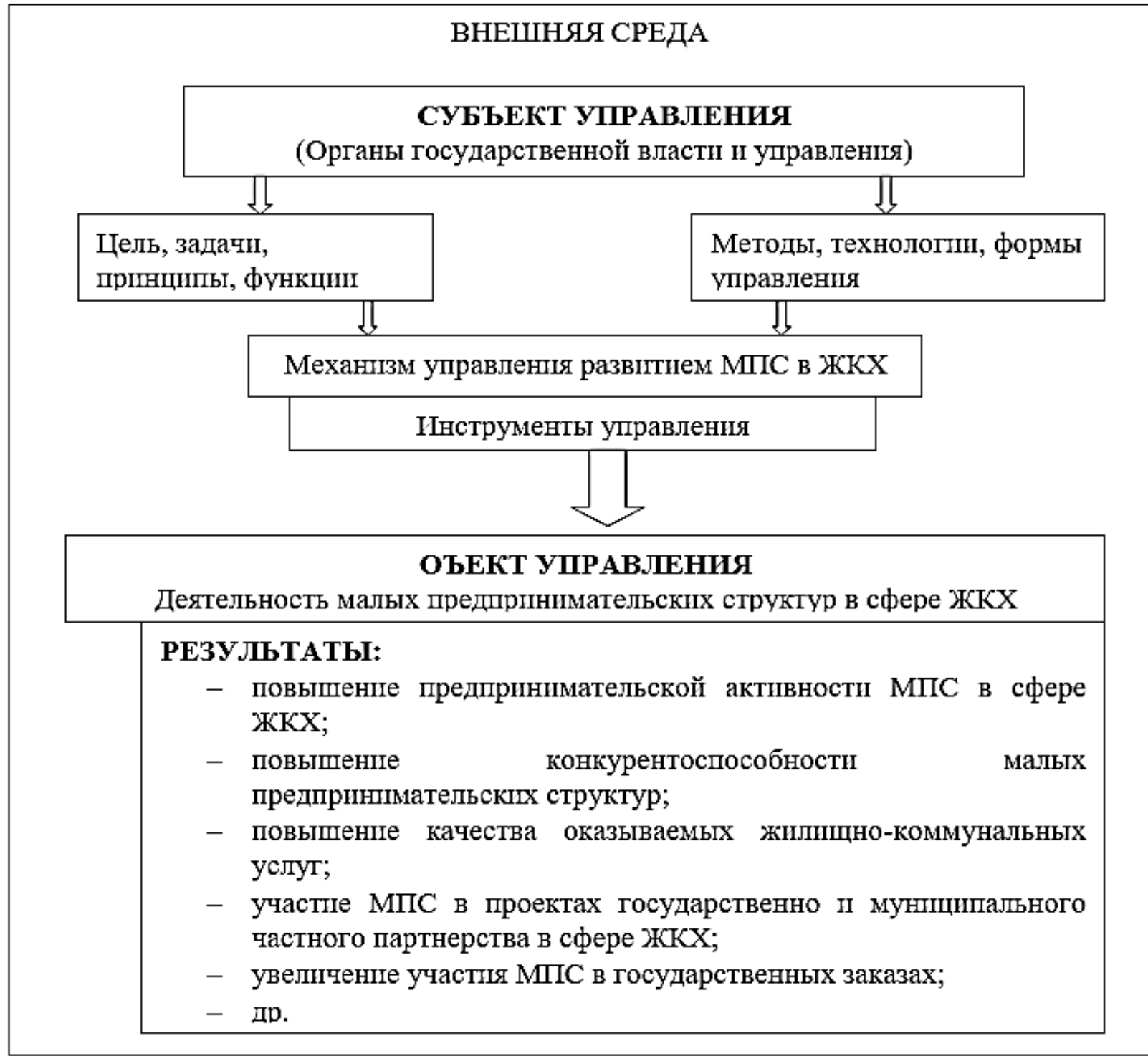

Рис. 1. Модель управления развитием малых предпринимательских структур в ЖКХ

Внешняя среда деятельности организаций задает предпринимательским структурам направление развития. Вследствие этого представляется важным отслеживание изменений во внешней среде и своевременное реагирование.

В качестве субъектов управления малыми предпринимательскими структурами в ЖКХ могут выступать органы государственной власти, структуры поддержки субъектов малого предпринимательства.

Целью управления развитием малых предпринимательских структур в ЖКХ является создание условий для наиболее эффективного функционирования предприятий в данной сфере. 
В теоретическом и практическом плане важны точность терминологии в управлении развитием предпринимательских структур и определении логической последовательности данного процесса. В связи с чем, разработана модель управления развитием предпринимательских структур в ЖКХ, в которой представлены элементы, виды, методы, субъекты и объекты управления развитием малых предпринимательских структур в ЖКХ.

\section{Сиисок литературы}

1. Ананьев А.А. Модель менеджмента для экономики, основанной на знаниях // Управление развитием малых и средних предпринимательских структур. - М.: Московский государственный университет экономики, статистики и информатики, 2014. - С. 64-65.

2. Смирнов В.В. Аспекты эффективного управления социально-экономическим развитием // Аудит и финансовый анализ. - 2009. - №3. - С. 3-14.

3. Постановление Правительства РФ от 15.04.2014 №316 «Об утверждении государственной программы Российской Федерации «Экономическое развитие и инновационная экономика».

4. Развитие малого и среднего предпринимательства Самарской области в 2015 году [Электронный ресурс]. http://economy.samregion.ru/activity/predprinim/itogi/razvitie-malogo-i-srednegopredprinimatelstva-samarskoy-oblasti-v-2015-godu/ (дата обращения: 25.12.2016).

5. Ковалева Т.М. Инструменты программно-целевого метода бюджетного планирования. - Самара: Самарский государственный экономический университет, 2014. - 11 (121).

Солодова Елена Петровна - старший преподаватель кафедры прикладной экономики и управления Самарского филиала ГАОУ ВО «Московский городской педагогический университет», Россия, Самара.

Solodova Elena Petrovna - senior lecturer at the Department of Applied Economics and Management of Samara Branch SAEI of HE «Moscow City University of Pedagogy», Russia, Samara. 